\title{
Tissue Engineering in Cleft Palate and Other Congenital Malformations
}

\author{
NICHOLAS J. PANETTA, DEEPAK M. GUPTA, BETHANY J. SLATER, MATTHEW D. KWAN, KAREN J. LIU, \\ AND MICHAEL T. LONGAKER
}

Department of Surgery, Stanford University School of Medicine, Stanford, California 94305-5148

\begin{abstract}
Contributions from multidisciplinary investigations have focused attention on the potential of tissue engineering to yield novel therapeutics. Congenital malformations, including cleft palate, craniosynostosis, and craniofacial skeletal hypoplasias represent excellent targets for the implementation of tissue engineering applications secondary to the technically challenging nature and inherent inadequacies of current reconstructive interventions. Apropos to the search for answers to these clinical conundrums, studies have focused on elucidating the molecular signals driving the biologic activity of the aforementioned maladies. These investigations have highlighted multiple signaling pathways, including Wnt, fibroblast growth factor, transforming growth factor- $\beta$, and bone morphogenetic proteins, that have been found to play critical roles in guided tissue development. Furthermore, a comprehensive knowledge of these pathways will be of utmost importance to the optimization of future cell-based tissue engineering strategies. The scope of this review encompasses a discussion of the molecular biology involved in the development of cleft palate and craniosynostosis. In addition, we include a discussion of craniofacial distraction osteogenesis and how its applied forces influence cell signaling to guide endogenous bone regeneration. Finally, this review discusses the future role of cell-based tissue engineering in the treatment of congenital malformations. (Pediatr Res 63: 545-551, 2008)
\end{abstract}

$\mathrm{T}$ he surgeon's scalpel has over the years served as the mainstay of therapy for cleft palate, craniosynostosis, and hypoplasias of the craniofacial skeleton. As a result of advances in the fields of molecular biology, developmental biology, stem cell biology, and material sciences, the potential for alternative or adjunctive therapies to surgical treatment of these congenital malformations has become a realistic possibility. This possibility exists in the form of tissue engineering. This review focuses on these three congenital malformations because of the tremendous potential for tissue engineering applications to provide more effective and minimally invasive treatment modalities for these conditions.

Furthermore, a focused discussion of each one of these congenital malformations serves to illustrate how an understanding of the biologic underpinnings of the pathology can lead to targeted interventions at the molecular level. Although much of these efforts remain in animal models, they lay the important foundation for development of future clinical treat-

Received December 3, 2007; accepted December 23, 2007

Correspondence: Michael T. Longaker, M.D., M.B.A., Stanford University School of Medicine, 257 Campus Drive, Stanford, CA 94305-5148; e-mail: longaker@ stanford.edu.

DOI: 10.1203/PDR.0b013e31816a743e ments. In the discussion of cleft palate, we focus on Wnt signaling. We used a novel system that has been used to dissect out the role of glycogen synthase-kinase 3 beta (GSK$3 \beta$ ), a key player in Wnt signaling, in regulating palatal development. Our discussion of craniosynostosis centers around fibroblast growth factor (FGF) signaling, the predominantly aberrant pathway in syndromic forms of the condition, and how an understanding of its signaling mechanisms has led to investigations of targeted molecular treatments. Our review will also discuss the correction of craniofacial skeletal hypoplasias with distraction osteogenesis (DO), a modality that is a form of endogenous tissue engineering. Finally, we will conclude with a discussion of how cell-based therapies stand poised to benefit from all of the molecular lessons previously gleaned.

\section{CLEFT PALATE}

Cleft palate is a relatively common congenital malformation with an incidence of between one and two in 1000 live births (1). The severity is variable and ranges from occult to overt; the causes are numerous and range from syndromic/ genetic to teratogenic/environmental to isolated/idiopathic; the management is often complex and ranges from straightforward surgical closure to multidisciplinary surgical and cleft team care. Furthermore, the socioeconomic burden posed by orofacial clefting is significant; according to the Healthcare Cost and Utilization Project, these costs often exceed $\$ 100$ million annually (2).

Surgical repair of cleft palate is currently the clinical standard of care. In these cases, affected children often require multiple physiologically challenging operations to address not only palate closure, but also associated problems with speech, dental occlusion, fluid buildup within the ears, and maxillary growth deficiency. As such, recent research has made strides at elucidating both the biology underlying normal palate development and the pathogenesis of cleft palate in attempts to improve the way cleft palate is managed in the future.

The process of palatogenesis depends on highly coordinated, anatomically specific and precisely timed molecular

\footnotetext{
Abbreviations: ASC, adipose-derived stromal cells; BMP, bone morphogenetic proteins; DO, distraction osteogenesis; ERK, extracellular signalrelated kinase; FGF, fibroblast growth factor; FGFR, fibroblast growth factor receptor; GSK3 $\boldsymbol{\beta}$, glycogen synthase kinase-3 beta; TGF $\boldsymbol{\beta}$, transforming growth factor beta
} 
signals for normal development (3). Among them, cell migration, proliferation, fusion, apoptotic, and differentiation events contribute to the complexity of craniofacial organization. In addition, multiple signaling pathways including sonic hedgehog, FGF, and transforming growth factor- $\beta$ (TGF- $\beta$ ) signaling complement each other. Aberration from any of this programming is likely to lead to pathogenesis of the palate, namely cleft palate (4). Much of our knowledge of craniofacial clefting arises from patient studies and selected animal models. Study of these models has revealed a well orchestrated sequence of events that has now been well documented (5).

Throughout the process of palatogenesis, molecular signaling between the mesenchymal and epithelial layers guides appropriate development. This paradigm of development is not specific to the palate, but the pathways underlying these interactions are temporally and spatially distinct and have not been clearly elucidated in the past. Learning what molecules are involved during the well-described classical stages of palate development allows for identification of missteps that may arise.

In an effort to further understand one aspect of the complex biology underlying normal palatogenesis, we recently investigated the role of GSK-3 $\beta$ in the process (6). In this system, we showed that cleft palate resulting from loss of GSK-3 $\beta$ could be rescued by protein stabilization during a short, specific window in embryogenesis in the mouse model. In this series of experiments, a mutant mouse carrying alleles for GSK-3 $\beta^{\text {FRB* }^{*}}$ was injected with rapamycin to inducibly stabilize GSK-3 $\beta$ during various 2 -d windows in embryogenesis within the timeline of palate development. This transgenic mouse was engineered to carry alleles for GSK-3 $\beta$ such that without drug addition the unstable FRB* tag would necessarily cause protein degradation, and the mouse would exhibit a null mutation phenocopy (i.e., cleft palate). Subsequent histologic analysis revealed that without rapamycin, no GSK$3 \beta^{\mathrm{F}^{*} / \mathrm{F}^{*}}$ embryos were able to rescue the cleft palate; however, with rapamycin injection of the pregnant dam between E13.5 and E15.0, the majority of conditional GSK-3 $\beta^{\mathrm{F}^{*} / \mathrm{F}^{*}}$ mutant animals were able to be partially or completely rescued from their cleft palate in utero. Rescue was not seen in other injection windows during palatogenesis, suggesting a critical role for GSK-3 $\beta$ function in normal palatogenesis between E13.5 and E15.0 in the mouse model (6).

GSK-3 $\beta$ has been implicated as a key regulator of a wide variety of developmentally important molecular pathways including Wnt, nuclear factor of activated T-cells (NFAT), Hedgehog, and insulin signaling. These signaling pathways are essential components of many biologic responses and associated diseases, including embryonic development and cell fate determination, diabetes, neurodevelopment and neurodegeneration, psychiatric disorders, cell cycle regulation and cancer, hematopoiesis, and immunity $(7,8)$. GSK-3 $\beta$ has not previously been implicated in the development of the mammalian palate. However, because it is positioned at the "node" of so many significant developmental pathways, analysis of GSK- $3 \beta$ function during palatogenesis will likely provide important insight into this common birth defect. In addition, because of the "promiscuous" nature of GSK-3 $\beta$, it has become a potentially important therapeutic target. Thus, many potent and selective inhibitors of GSK-3 $\beta$ function are being developed by the pharmaceutical industry (9).

Although GSK-3 $\beta$ mutations have not been documented to be a cause of human orofacial clefting, our recent findings suggest it is clinically relevant because of the potential to devise methods for improved treatments, including in utero rescue, for human orofacial clefting. Ongoing investigations of GSK-3 $\beta$ 's role in palatogenesis promise future clinical applicability, because it has the potential to reveal signaling pathways underlying cleft formation and lay the groundwork for potentially improved treatments using small molecules.

Within the last several years, there have also been numerous reports of TGF- $\beta 3$ 's role in palatogenesis. In 2001, Koo et al. first reported a novel mutant mouse that could potentially be used as an animal model for the study of cleft palate (10). In this report, they described a mutant mouse that was homozygous null for TGF- $\beta 3$ on both alleles. They reported 100\% clefting of the palate in the homozygous TGF- $\beta 3$ knockout pups. Changes in TGF- $\beta 3$ have also been associated with orofacial clefting in humans, further bolstering the significance of Koo et al.'s report. Subsequent to the development of the animal model for TGF- $\beta 3$-mediated clefting, several reports have demonstrated that restoration of TGF- $\beta$ signaling was sufficient to rescue at least part of the cleft phenotype. In particular, Cui et al. demonstrated that downstream TGF- $\beta$ signaling element Smad2 expression in the palatal shelf medial edge epithelia rescued much of the cleft secondary palate in TGF- $\beta 3$ null mice (11). Yang and Kaartinen have also recently reported rescue by TGF- $\beta$ signaling (12). In this report, TGF- $\beta 1$ was knocked into the TGF- $\beta 3$ locus in TGF- $\beta 3$ null mice; the result was similar to the aforementioned report by Cui et al. in that a significant portion of the secondary palate was rescued. Finally, Spivak et al. have reported rescue of the cleft palate phenotype in TGF- $\beta 3$ null pups in utero by viral-mediated delivery of TGF- $\beta 3$ during palatogenesis with substantial success, perhaps setting the stage for future in utero gene therapy for craniofacial disease processes (13). In summary, TGF- $\beta$ signaling has long been recognized as a critical mediator of successful palatogenesis, and it will be interesting to follow further research in this field toward clinical translation into alternative strategies for the management of cleft palate.

Finally, Wnt signaling has recently received considerable attention for its role in craniofacial morphogenesis, including orofacial clefting. Several reports discuss changes in Wnt family member gene expression in association with cleft palate, but only recently was loss of Wnt9b purported to be causal in the etiology of cleft palate in a mouse model (14). In this report, the authors confirmed that the previously described mutation clf1 in A/WySn mice was a mutation of the Wnt9b gene by a standard genetic test of allelism. The authors conclude by suggesting future examination of Wnt9b loci in humans with nonsyndromic cleft lip with or without cleft palate. Indeed, it appears that modulation of Wnt signaling holds promise for more effective management strategies in cases of orofacial clefting in the future, and it will be exciting to follow this line of research as it matures. 


\section{CRANIOSYNOSTOSIS}

Advances in genetics and the advent of transgenic mice have contributed greatly to the fund of knowledge regarding specific pathways that control both normal and abnormal cranial suture fusion. Cranial sutures, which form as the bones of the skull vault approximate one another during development, serve as sites of bone growth. The patency of these bony joints during development allows the cranial vault to expand and accommodate the growing brain. Under physiologic conditions, bone deposition at the cranial sutures is regulated by molecular boundaries. Under pathologic conditions, these boundaries become obscured and premature fusion of one or more cranial sutures, or craniosynostosis, can occur. An understanding of the molecular mechanisms dictating these events carries important implications for the development of novel therapies for craniosynostosis. However, given that premature suture fusion can be thought of in its most basic terms as abnormal bone formation, the molecular lessons gleaned from an understanding of cranial suture biology are also broadly applicable toward skeletal tissue engineering applications.

Craniosynostosis has a reported incidence of approximately one in 2000 to 2500 live births world-wide $(15,16)$. Premature fusion of cranial sutures leads to a restriction of brain growth and can result in a dysmorphic cranial vault, as well as a multitude of serious functional and morphologic consequences. Current surgical approaches to this disorder consist primarily of performing linear craniotomies to excise the synostosed suture or sutures and cranial vault remodeling procedures, such as fronto-orbital advancement, early in life. However, these procedures are physiologically challenging for young children and are often associated with refusion of the suture after surgical correction. In addition, these highly invasive operations are associated with a number of complications such as infection, bleeding, and the need for frequent blood transfusions $(17,18)$. Thus, there is a great demand for improved strategies for treating craniosynostosis. Ultimately, the goal of tissue engineering in this context is to convert our understanding of the molecular mechanisms controlling suture biology into minimally invasive, molecular-based therapies to correct and prevent premature cranial suture fusion.

Our laboratory has been particularly interested in noggin, a secreted antagonist of bone morphogenetic proteins (BMP). Upon evaluating levels of BMP in fusing and patent sutures of mice, Warren et al. found no difference (19). However, a screen of BMP antagonists revealed noggin to be expressed in patent, but not fusing, cranial sutures. This differential expression suggested that the fate of a cranial suture, that is fusion or maintenance of patency, might be controlled by the relative amounts of antagonist to agonist, rather than by the absolute amount of agonist. To test this hypothesis, Warren et al. injected a noggin-expressing adenovirus into normally fusing posterior frontal sutures in both an in vitro calvaria culture system and an in vivo mouse model (19). In both models, the injected sutures were found to be abnormally patent. Thus, the mis-expression of noggin had profound consequences on cranial suture fate, raising the possibility that noggin could be exploited for therapeutic purposes. Recently, Cooper et al. demonstrated the potential clinical application for noggin in their rabbit model of familial nonsyndromic craniosynostosis (20). After performing suturectomy on the fused sutures, the authors implanted noggin-loaded gels into the suturectomy sites. They subsequently found significantly decreased rates of suture refusion in rabbits treated with noggin, compared with sham-treated rabbits.

Interestingly, Warren et al. also found that noggin expression is suppressed by FGF-2 (19). Based on this finding, Warren et al. proposed that syndromic, FGF receptor (FGFR)mediated craniosynostosis might be the result of inappropriate down regulation of noggin expression. When examining the known mutations of craniosynostosis, gain-of-function mutations of the FGFR family have been shown to be the cause of approximately $20 \%$ of all known craniosynostosis disorders, including Crouzon, Apert, Pfeiffer, and Jackson-Weiss (21). Mutations of the FGFRs in these syndromes have been described to cause aberrant signaling via three main mechanisms: receptor dimerization resulting in constitutive activation, increased ligand affinity, and removal of inhibition (22). As an example, Crouzon syndrome can be the result of constitutive activation of FGFR-2 through receptor dimerization of its free cysteines (23).

Given the prevalence of FGFR mutations, several investigators have attempted to manipulate this receptor in animal models to nonsurgically mitigate the premature fusion of sutures associated with FGFR mutations. In an organ culture model, Eswarakumar et al. described the application of PLX052, a small-molecule inhibitor of FGFR, to calvaria harvested from embryonic day 18.5 Crouzon-like mutant mice and wild-type mice (24). PLXO52 is a novel inhibitor created by chlorination and a chemical substitution. With the addition of this drug, the autophosphorylation of Fgfr2c is inhibited, which in turn blocks the phosphorylation of Frs $2 \alpha$, ultimately preventing dimerization of the mutant receptor. After $2 \mathrm{wk}$ of exposure to PLXO52 in organ culture, the authors found the premature fusion of sutures in calvaria of Crouzon-like mice to be prevented, whereas the growth of the wild-type calvaria was unaffected. Although performed in an organ culture system, these results highlight specific, small-molecule inhibitors that can be used to pinpoint signaling elements involved in the pathologic state. Such information will be critical for future development of targeted molecular therapies of craniosynostosis.

This point was further demonstrated by Perlyn et al. who used a similar pharmacological strategy, using PD173074, a selective FGFR tyrosine kinase inhibitor, as a treatment for craniosynostosis syndromes caused by constitutive FGFR activation (22). The authors also used a mouse whole calvaria culture system to compare skulls of mutant mice with a Crouzon-like phenotype versus skulls of wild-type mice in the presence of the inhibitor for $2 \mathrm{wk}$. Upon histologic analysis, they found that mutant calvaria exposed to PD173074 demonstrated patency of the coronal sutures with its characteristic overlapping pattern.

Parallel to efforts aimed at disrupting aberrant FGF signaling at the receptor level, efforts have also been directed at 
investigating strategies that block abnormal signaling at the gene transcript level. With the recent explosion of RNA interference technology, this tool has now been applied to craniosynostosis. Shukla et al. generated a small hairpin RNA targeted at the mutant form of Fgfr $2\left(F g f r 2^{S 252 W}\right)$, which is responsible for the Apert-like craniosynostosis syndrome in mice (25). When transgenic mice expressing this small hairpin RNA were crossed with mutant mice carrying the constitutively activated form of FGFR2, the Apert-like phenotype in the progeny was prevented. The authors also demonstrated that in calvarial cultures from the mutant $F g f r 2^{S 252 W}$ mice, greater amounts of phosphorylated extracellular signal-related kinase (ERK)1/2, a downstream mediator of FGF signaling (26-28), were present in comparison to calvarial cultures from wild-type mice. As further confirmation that the aberrant FGF signaling in these $F g f r 2^{S 252 W}$ mice was due to ERK1/2 signaling, the authors administered U0126, a pharmacological inhibitor of ERK phosphorylation. They found that administration of the drug to the mice during embryonic and early postnatal stages significantly repressed the craniosynostosis phenotype in the FGFR2 mutant mouse model. This study elegantly demonstrates both the utility of RNA interference for probing specific signaling pathways and the potential for its eventual application in the clinical realm.

Taken together, these experiments indicate the importance of continued investigation of the complex pathways and relationships among the genes and mitogens responsible for craniosynostosis. These studies may have potential for exploitation in tissue engineering strategies to treat diseases caused by specific mutations. For instance, noggin, or specific FGFR inhibitors could be locally delivered to prevent premature suture fusion and also refusion, commonly associated after correction of synostosed sutures. Furthermore, an understanding of the molecular pathways guiding cranial suture biology can also provide insight into the mechanism that regulates bone formation.

\section{DISTRACTION OSTEOGENESIS}

DO is now accepted as the standard for correction of a wide range of craniofacial skeletal hypoplasias. DO can be viewed as a form of endogenous tissue engineering, whereby the discrete application of force vectors results in robust bone formation. First described by Alessandro Codivilla in 1905 and later popularized by Gavril Ilizarov, DO was initially a modality applied for the treatment of long bone deficits (2931). During the 1970 s, studies were initiated to investigate the application of DO to the craniofacial skeleton in animal models. Translation of this work to the clinical arena was finally realized in 1992 when McCarthy et al. reported the application of DO to treat a hypoplastic mandible (32). DO, in its most basic form, involves an osteotomy and application of distraction hardware to the bone of interest. After the osteotomy, the two bone edges are left unperturbed during the latency period, allowing an initial fracture callus to form and the regional accumulation of cytokines and growth factors to recruit and organize osteoblast and osteoclast activity (33). This is followed by the activation phase, when the bony segments are moved apart from one another, which usually progresses at a rate of 0.5 to $2 \mathrm{~mm}$ per day, until the desired degree of distraction is obtained (33). Complications arising from an improper rate of distraction include fibrous union and premature consolidation, depending on whether the process was too expeditious or delayed, respectively (33). Activation is finally followed by a period of consolidation, allowing for maturation of the skeletal regenerate.

Today, DO has revolutionized the treatment of both syndromic and nonsyndromic congenital craniofacial malformations. The technique has been successfully applied to the treatment of skeletal hypoplasias involving the mandible (hemifacial microsomia, Pierre Robbins Sequence, Treacher Collins Syndrome, Stickler Syndrome, Nager Syndrome), midface (cleft lip and palate, Crouzon Syndrome, Apert Syndrome, Pfeiffer Syndrome), upper face, orbits, and cranial vault (craniosynostosis). The severity of anatomical derangement and resultant functional sequelae of patients eligible for craniofacial DO is highly variable. In cases of mandibular hypoplasia, or situations in which the mandible is posteriorly displaced from proper anatomic position, an increasing portion of the tongue becomes resident in the oropharynx and hypopharynx (33). This retroversion of oral soft tissue can result in significant airway obstruction, often mandating tracheostomy or endotracheal intubation (34). Additionally, these anatomical irregularities are the source of considerable feeding difficulties, leading to failure to thrive (35). Newborns afflicted with craniosynostosis can experience multiple physiologic and developmental derangements because of their anatomical anomalies. Elevated intracranial pressures, visual disturbances, as well as impaired cognitive maturation can result, and the aim of surgical intervention is to alleviate these symptoms, while restoring normal intracranial volume and skeletal structure (34). Proponents of craniofacial DO argue that it is both less invasive than traditional reconstructive procedures and has the added advantage of gradually extending the accompanying soft tissue envelope along with the underlying bone.

Research in the field of DO has most importantly served to highlight the influence of mechanical forces on osteogenesis. The observation made by Carter et al. that tensile forces drive osteogenesis, whereas compressive forces promote chondrogenesis, has provided a useful lens with which to view DO (36). Expounding on this concept, Loboa et al. reported that tensile strain ranging from 10 to $12.5 \%$ during distraction yielded an environment advantageous for de novo bone regeneration (37). Subsequently, by implementing three-dimension finite element analyses and making comparisons to histologic patterning in bony regenerates, regional tissue responses to tensile and hydrostatic forces across the regenerate were defined (38). Loboa et al. found that regions exposed to tensile strains of $13 \%$ or less corresponded to bone regeneration, whereas low periosteal hydrostatic pressures were associated with cartilaginous differentiation. In efforts to further dissect the influence of mechanical forces on osteogenesis at a cellular level in vitro, Gabbay et al. used a microdistraction device capable of applying linear forces in a three-dimensional environment (39). MC3T3 preosteoblasts were suspended in three- 
dimensional collagen gels and exposed to either continuous distraction, or cyclical distraction and compression. It was observed that continuous distraction drove cellular proliferation, whereas cyclical distraction and compression encouraged the progression to a differentiated phenotype.

Necessary to successful endogenous bone tissue engineering in the setting of DO is the transduction of biomechanical forces into molecular signals that orchestrate bone regeneration. Extending our knowledge of this intricate process, Rhee et al. have identified signaling pathways that appear to function specifically in the process of translating mechanical strain into guided osteogenesis $(40,41)$. They observed that expression of both c-Src, a kinase in the integrin mediated signaling pathway, as well as ERK1/2, a key modulator of mesenchymal stem cell differentiation, were up-regulated during distraction. Concurrently, expression of these factors was not significantly elevated in the healing of critical and noncritical sized osteotomies. Additionally, elevated levels of both of these proteins coincided with elevated levels of BMP 2/4, suggesting that signaling pathways responsible for the mechanotransduction of external forces resulting from DO may play a role in the resultant process of organized skeletal regeneration.

The importance of angiogenesis, and the forces driving circulating progenitor cells to localize to wounds and promote neovascularization, has garnered considerable interest from researchers. Sojo et al. were able to demonstrate that neovascularization precedes osteogenesis (42). After femoral distraction in rats, vascular endothelial growth factor (VEGF) and BMP immunohistochemical staining was performed, revealing that induction of angiogenesis occurred before bone regeneration. Fang et al. further established the importance of angiogenesis to endogenous bone regeneration by demonstrating that decreased angiogenesis led to impaired healing (43). Subsequent to the administration of the angiogenic inhibitor TNP-470, fibrous nonunion in rat mandibles undergoing distraction was observed. In light of such findings, the potential to derive enhanced osteogenesis by means of augmenting angiogenesis will serve as a target for future studies.

Of note, recent work by Ceradini et al. has furthered our understanding of the role of ischemic signals in eliciting circulating progenitor cells in the setting of DO (44). In their studies, they outlined the process by which progenitor cells are recruited to areas of tissue ischemia through elevated expression of hypoxia-inducible factor- 1 in endothelial cells. Increased hypoxia-inducible factor-1 induces expression of stromal cell-derived factor-1, potentiating the conscription of progenitor cells to hypoxic tissue. In an effort to elucidate microenvironmental cues driving neovascularization during DO, Cetrulo et al. examined whether endothelial progenitor cells responded to local ischemia produced by distraction. The authors found that by injecting fluorescently labeled endothelial progenitor cells at the start of activation, it was revealed that they are sequestered to the relatively ischemic environment of the regenerating tissue (45). This finding reinforces the microniche created by a region of injury and identifies specific factors that are required for successful bone formation.

\section{A CELL-BASED APPROACH}

Our discussion has heretofore focused on the molecular mechanisms involved with the pathologic processes of cleft palate and craniosynostosis or environmental factors dictating successful bone formation. Arguably, however, application of these factors toward a cell-based approach may offer the best solution. As pediatric craniofacial surgeons treating cleft palates, craniosynostosis, and craniofacial skeletal hypoplasias are commonly confronted with the challenge of replacing or reconstructing tissue deficits, cell-based therapies offer a paradigm shift as to how these tissue deficits should be addressed. Strategies that simply seek to repair or reconstruct missing tissue are no longer adequate. Instead, the overarching goal is to regenerate the missing tissue in a patient specific manner.

Advances in our understanding of multipotent cells over the last half century have fueled a cell-based approach. At the core of such a strategy is the ability to harvest a sufficient quantity of progenitor cells, which when given the proper environmental cues are capable of regenerating the missing tissue such that it functionally and structurally mimics endogenous tissue. Because lineage-committed cells are often limited in quantity and in their potential for expansion, attention has turned to stem cells to fill this void. When considering stem cells, a pyramid of cellular pluripotency exists, with embryonic stem cells undoubtedly occupying the apex (46). Derived from the inner cell mass of the blastocyst, embryonic stem cells possess the ability to differentiate along endodermal, ectodermal, and mesodermal lineages. However, because of the ethical and political debate currently surrounding the use of embryonic stem cells, substantial efforts have been directed at characterizing alternative sources of stem cells, which maybe more limited in their multilineage potential $(47,48)$. These include amniotic fluid, umbilical cord blood, bone marrow, subcutaneous (s.c.) fat, and dental pulp, among others (49-53). The recent description by two independent groups, of induced pluriopotency in adult, somatic cells by turning on select genes, has added yet another exciting twist to the burgeoning stem cell field $(54,55)$.

Missing bone is a common challenge that spans all three of the previously discussed congenital disorders, and our laboratory has taken particular interest in a cell-based approach to this problem. Although other tissue deficits, involving mucosa, cartilage, and muscle exist, the broad lessons gleaned from cell-based, skeletal tissue engineering can also be applied to regeneration of these other tissues. In cleft palate patients, the surgeon is often confronted with bony defects of the alveolus. Similarly, in syndromic forms of craniosynostosis where complex remodeling procedures are performed, sizeable calvarial defects can often result. The gold standard material for reconstructing these defects remains autogenous bone grafts. Autogenous bone grafts, however, are accompanied by concerns for donor site morbidity and limited quantities $(56,57)$. A host of allogeneic and synthetic materials are available as well, but they also have their inherent disadvantages, including risk of infection, immunologic issues, structural integrity, and contouring abnormalities (57). Finally, although DO has tremendously improved outcomes in the 
treatment of hypoplasias of the craniofacial skeleton, it is also not without its own morbidities including soft tissue infection, osteomyelitis, pin-tract loosening or infection, hardware failure, and patient discomfort (58).

In terms of skeletal tissue engineering in the craniofacial region, substantial research has been directed at investigating two cell sources, bone marrow and adipose tissue. Since Pittenger et al.'s description of the multipotent nature of bone marrow-derived mesenchymal cells, bone marrow has served as the traditional source of skeletal progenitor cells (51). When seeded on a variety of scaffolds in both endochondral and membranous bone defects, bone marrow mesenchymal cells have demonstrated the potential for regenerating skeletal tissue.

Since Zuk et al.'s first description of multipotent cells within s.c. adipose tissue, our laboratory and others have taken interest in the potential of adipose-derived stromal cells (ASC) for skeletal tissue engineering applications $(52,59)$. Because of the relative accessibility, safety of harvest, and abundance of s.c. fat, ASC are an attractive candidate for cell-based therapies. We have demonstrated as proof of principal the ability of these cells to regenerate bone in critical-sized calvarial defects (60). Mouse-derived ASC were seeded on apatite-coated, poly(lactic-co-glycolic acid) (PLGA) scaffolds and implanted into $4 \mathrm{~mm}$, parietal bone defects. By $12 \mathrm{wk}$, substantial bone formation was observed in calvarial defects treated with ASC, comparable to the amount of bone formation observed in groups treated with bone marrow stromal cells and osteoblasts. This finding has recently been generalized to human-derived ASC in a nude mouse model. Yoon et al. reported on greater calvarial healing in nude mice where defects were implanted with human ASC-seeded PLGA scaffolds in comparison to mice treated with scaffolds alone (61).

The identification of postnatal sources of multipotent cells has been instrumental in the development of cell-based approaches for tissue engineering. As evidenced by the recent descriptions of induced pluripotency, this field continues to evolve. Ultimately, efforts are geared toward understanding what cues guide these multipotent cells along a given lineage. Molecular lessons gleaned from studies in cleft palate, cranial suture biology, and DO can be similarly applied to these multipotent cells.

\section{CONCLUSION}

The potential contributions that tissue engineering proffers for children afflicted with congenital craniofacial malformations are significant. Yet, the untapped potential of regenerative medicine far surpasses the advances that have been appreciated to date. Multidisciplinary efforts continue to highlight the field of regenerative medicine as a realistic source of novel therapeutics. Initiatives to decipher the molecular blueprint guiding skeletal development and regeneration serve as a template for regenerative efforts for other tissues. Critical to the forward progress of such work is an understanding of the molecular mechanisms that underlie both physiologic (e.g., palate fusion, suture patency) and pathologic (e.g., cleft palate, craniosynostosis) processes. Elucidation of these mechanisms provides the stepping-stone for developing novel, molecularbased therapies for these congenital malformations. Furthermore, an understanding of the molecular mechanisms guiding specific biologic processes also provides insight into the molecular cues needed for cell-based strategies. Although cleft palates, craniosynostosis, and craniofacial skeletal hypoplasias continue to be corrected through surgery, ongoing investigations of these malformations bring us closer to tissue engineering-based therapies.

\section{REFERENCES}

1. Robin NH, Baty H, Franklin J, Guyton FC, Mann J, Woolley AL, Waite PD, Grant J 2006 The multidisciplinary evaluation and management of cleft lip and palate. South Med J 99:1111-1120

2. HCUP 2007 Healthcare Cost and Utilization Project. Agency for Healthcare Research and Quality, Rockville, MD. Available at: http://www.ahrq.gov/data/hcup/

3. Chai Y, Maxson RE Jr 2006 Recent advances in craniofacial morphogenesis. Dev Dyn 235:2353-2375

4. Kerrigan JJ, Mansell JP, Sengupta A, Brown N, Sandy JR 2000 Palatogenesis and potential mechanisms for clefting. J R Coll Surg Edinb 45:351-358

5. Jin JZ, Ding J 2006 Analysis of cell migration, transdifferentiation and apoptosis during mouse secondary palate fusion. Development 133:3341-3347

6. Liu KJ, Arron JR, Stankunas K, Crabtree GR, Longaker MT 2007 Chemical rescue of cleft palate and midline defects in conditional GSK-3beta mice. Nature 446:79-82

7. Doble BW, Woodgett JR 2003 GSK-3: tricks of the trade for a multi-tasking kinase. J Cell Sci 116:1175-1186

8. Cohen P, Frame S 2001 The renaissance of GSK3. Nat Rev Mol Cell Biol 2:769-776

9. Meijer L, Flajolet M, Greengard P 2004 Pharmacological inhibitors of glycogen synthase kinase 3. Trends Pharmacol Sci 25:471-480

10. Koo SH, Cunningham MC, Arabshahi B, Gruss JS, Grant JH 2001 The transforming growth factor-beta 3 knock-out mouse: an animal model for cleft palate. Plast Reconstr Surg 108:938-948; discussion 949

11. Cui X-M, Shiomi N, Chen J, Saito T, Yamamoto T, Ito Y, Bringas P, Chai Y, Shuler CF 2005 Overexpression of Smad2 in Tgf-beta3-null mutant mice rescues cleft palate. Dev Biol 278:193-202

12. Yang LT, Kaartinen V $2007 \mathrm{Tgfb} 1$ expressed in the Tgfb3 locus partially rescues the cleft palate phenotype of Tgfb3 null mutants. Dev Biol 312:384-395

13. Spivak RM, Endo ME, Zajac A, Zoltick P, Ang B, Horn R, Flake A, Kirschner R, Nah H-D 2007 In utero gene delivery of adenovirus encoded TGF-beta3 restores physiologic palatal fusion and rescues cleft palate in a TGF-beta3 knockout mouse. J Am Coll Surg 205:S92

14. Juriloff DM, Harris MJ, McMahon AP, Carroll TJ, Lidral AC 2006 Wnt9b is the mutated gene involved in multifactorial nonsyndromic cleft lip with or without cleft palate in $\mathrm{A} / \mathrm{WySn}$ mice, as confirmed by a genetic complementation test. Birth Defects Res A Clin Mol Teratol 76:574-579

15. Lajeunie E, Le Merrer M, Bonaïti-Pellie C, Marchac D, Renier D 1995 Genetic study of nonsyndromic coronal craniosynostosis. Am J Med Genet 55:500-504

16. Posnick JC 2000 Craniofacial syndromes and anomalies. In: Posnick JC (ed) Craniofacial and Maxillofacial Surgery in Children and Young Adults. W.B. Saunders, Philadelphia, pp 391-527

17. Shin J, Persing JA 2007 Non-syndromic craniosynostosis and deformational plagiocephaly. In: Thorne CH (ed) Grabb and Smith's Plastic Surgery. Lippincott, Williams, and Wilkins, Philadelphia, PA

18. Whitaker LA, Bartlett SP, Schut L, Bruce D 1987 Craniosynostosis: an analysis of the timing, treatment, and complications in 164 consecutive patients. Plast Reconstr Surg 80:195-212

19. Warren SM, Brunet LJ, Harland RM, Economides AN, Longaker MT 2003 The BMP antagonist noggin regulates cranial suture fusion. Nature 422:625-629

20. Cooper GM, Curry C, Barbano TE, Burrows AM, Vecchione L, Caccamese JF, Norbutt CS, Costello BJ, Losee JE, Moursi AM, Huard J, Mooney MP 2007 Noggin inhibits postoperative resynostosis in craniosynostotic rabbits. J Bone Miner Res 22:1046-1054

21. Passos-Bueno MR, Wilcox WR, Jabs EW, Sertie AL, Alonso LG, Kitoh H 1999 Clinical spectrum of fibroblast growth factor receptor mutations. Hum Mutat 14:115-125

22. Perlyn CA, Morriss-Kay G, Darvann T, Tenenbaum M, Ornitz DM 2006 A model for the pharmacological treatment of crouzon syndrome. Neurosurgery 59:210-215; discussion 210-215

23. Mangasarian K, Li Y, Mansukhani A, Basilico C 1997 Mutation associated with Crouzon syndrome causes ligand-independent dimerization and activation of FGF receptor-2. J Cell Physiol 172:117-125

24. Eswarakumar VP, Ozcan F, Lew ED, Bae JH, Tome F, Booth CJ, Adams DJ, Lax I, Schlessinger J 2006 Attenuation of signaling pathways stimulated by pathologically activated FGF-receptor 2 mutants prevents craniosynostosis. Proc Natl Acad Sci USA 103:18603-18608

25. Shukla V, Coumoul X, Wang R-H, Kim H-S, Deng C-X 2007 RNA interference and inhibition of MEK-ERK signaling prevent abnormal skeletal phenotypes in a mouse model of craniosynostosis. Nat Genet 39:1145-1150 
26. Shimoaka T, Ogasawara T, Yonamine A, Chikazu D, Kawano H, Nakamura K, Itoh N, Kawaguchi H 2002 Regulation of osteoblast, chondrocyte, and osteoclast functions by fibroblast growth factor (FGF)-18 in comparison with FGF-2 and FGF-10. J Biol Chem 277:7493-7500

27. Spector JA, Mathy JA, Warren SM, Nacamuli RP, Song HM, Lenton K, Fong KD, Fang DT, Longaker MT 2005 FGF-2 acts through an ERK1/2 intracellular pathway to affect osteoblast differentiation. Plast Reconstr Surg 115:838-852

28. Kim H-J, Lee M-H, Park H-S, Park M-H, Lee S-W, Kim S-Y, Choi J-Y, Shin H-I, Kim H-J, Ryoo H-M 2003 Erk pathway and activator protein 1 play crucial roles in FGF2-stimulated premature cranial suture closure. Dev Dyn 227:335-346

29. Ilizarov GA, Deviatov AA 1971 Surgical elongation of the leg. Ortop Travmato Protez 32:20-25

30. Codivilla A 1994 On the means of lengthening, in the lower limbs, the muscles and tissues which are shortened through deformity. Clin Orthop Relat Res 301:4-9

31. Ilizarov GA, Lediaev VI, Shitin VP 1969 [The course of compact bone reparative regeneration in distraction osteosynthesis under different conditions of bone fragment fixation (experimental study)]. Eksp Khir Anesteziol 14:3-12

32. McCarthy JG, Schreiber J, Karp N, Thorne CH, Grayson BH 1992 Lengthening the human mandible by gradual distraction. Plast Reconstr Surg 89:1-8

33. Bennett EC, Sidman JD 2002 Osteogenic distraction in the face. Facial Plast Surg Clin North Am 10:181-190

34. Matsumoto K, Nakanishi H, Kubo Y, Yokozeki M, Moriyama K 2003 Advances in distraction techniques for craniofacial surgery. J Med Invest 50:117-125

35. Singh DJ, Bartlett SP 2005 Congenital mandibular hypoplasia: analysis and classification. J Craniofac Surg 16:291-300

36. Carter DR, Beaupre GS, Giori NJ, Helms JA 1998 Mechanobiology of skeleta regeneration. Clin Orthop Relat Res S41-S55

37. Loboa EG, Fang TD, Warren SM, Lindsey DP, Fong KD, Longaker MT, Carter DR 2004 Mechanobiology of mandibular distraction osteogenesis: experimental analyses with a rat model. Bone 34:336-343

38. Loboa EG, Fang TD, Parker DW, Warren SM, Fong KD, Longaker MT, Carter DR 2005 Mechanobiology of mandibular distraction osteogenesis: finite element analyses with a rat model. J Orthop Res 23:663-670

39. Gabbay IS, Zuk PA, Tahernia A, Askari M, O'Hara CM, Karthikeyan T, Azari K, Hollinger JO, Bradley JP 2006 In vitro microdistraction of preosteoblasts: distraction promotes proliferation and oscillation promotes differentiation. Tissue Eng 12:30553065

40. Rhee ST, Buchman SR 2005 Colocalization of c-Src (pp60src) and bone morphogenetic protein $2 / 4$ expression during mandibular distraction osteogenesis: in vivo evidence of their role within an integrin-mediated mechanotransduction pathway. Ann Plast Surg 55:207-215

41. Rhee ST, El-Bassiony L, Buchman SR 2006 Extracellular signal-related kinase and bone morphogenetic protein expression during distraction osteogenesis of the mandible: in vivo evidence of a mechanotransduction mechanism for differentiation and osteogenesis by mesenchymal precursor cells. Plast Reconstr Surg 117:2243-2249

42. Sojo K, Sawaki Y, Hattori H, Mizutani H, Ueda M 2005 Immunohistochemica study of vascular endothelial growth factor (VEGF) and bone morphogenetic protein-2, -4 (BMP-2, -4) on lengthened rat femurs. J Craniomaxillofac Surg 33:238-245

43. Fang TD, Salim A, Xia W, Nacamuli RP, Guccione S, Song HM, Carano RA, Filvaroff EH, Bednarski MD, Giaccia AJ, Longaker MT 2005 Angiogenesis is required for successful bone induction during distraction osteogenesis. J Bone Miner Res 20:1114-1124

44. Ceradini DJ, Kulkarni AR, Callaghan MJ, Tepper OM, Bastidas N, Kleinman ME, Capla JM, Galiano RD, Levine JP, Gurtner GC 2004 Progenitor cell trafficking is regulated by hypoxic gradients through HIF-1 induction of SDF-1. Nat Med $10: 858-864$

45. Cetrulo CL Jr, Knox KR, Brown DJ, Ashinoff RL, Dobryansky M, Ceradini DJ, Capla JM, Chang EI, Bhatt KA, McCarthy JG, Gurtner GC 2005 Stem cells and distraction osteogenesis: endothelial progenitor cells home to the ischemic generate in activation and consolidation. Plast Reconstr Surg 116:1053-1064; discussion 1065-1057

46. Mimeault M, Hauke R, Batra SK 2007 Stem cells: a revolution in therapeutics-recen advances in stem cell biology and their therapeutic applications in regenerative medicine and cancer therapies. Clin Pharmacol Ther 82:252-264

47. Weissman IL 2002 Stem cells-scientific, medical, and political issues. N Engl J Med 346:1576-1579

48. Bahadur G 2003 The moral status of the embryo: the human embryo in the UK Human Fertilisation and Embryology (Research Purposes) Regulation 2001 debate. Reprod Biomed Online 7:12-16

49. De Coppi P, Bartsch G Jr, Siddiqui MM, Xu T, Santos CC, Perin L, Mostoslavsky G, Serre AC, Snyder EY, Yoo JJ, Furth ME, Soker S, Atala A 2007 Isolation of amniotic stem cell lines with potential for therapy. Nat Biotechnol 25:100-106

50. Lee OK, Kuo TK, Chen WM, Lee KD, Hsieh SL, Chen TH 2004 Isolation of multipotent mesenchymal stem cells from umbilical cord blood. Blood 103:16691675

51. Pittenger MF, Mackay AM, Beck SC, Jaiswal RK, Douglas R, Mosca JD, Moorman MA, Simonetti DW, Craig S, Marshak DR 1999 Multilineage potential of adult human mesenchymal stem cells. Science 284:143-147

52. Zuk PA, Zhu M, Ashjian P, De Ugarte DA, Huang JI, Mizuno H, Alfonso ZC, Fraser JK, Benhaim P, Hedrick MH 2002 Human adipose tissue is a source of multipoten stem cells. Mol Biol Cell 13:4279-4295

53. Gronthos S, Brahim J, Li W, Fisher LW, Cherman N, Boyde A, DenBesten P, Robey PG, Shi S 2002 Stem cell properties of human dental pulp stem cells. J Dent Res 81:531-535

54. Takahashi K, Tanabe K, Ohnuki M, Narita M, Ichisaka T, Tomoda K, Yamanaka S 2007 Induction of pluripotent stem cells from adult human fibroblasts by defined factors. Cell 131:861-872

55. Yu J, Vodyanik MA, Smuga-Otto K, Antosiewicz-Bourget J, Frane JL, Tian S, Nie J, Jonsdottir GA, Ruotti V, Stewart R, Slukvin II, Thomson JA 2007 Induced pluripotent stem cell lines derived from human somatic cells. Science 318:19171920

56. Mulliken JB, Glowacki J 1980 Induced osteogenesis for repair and construction in the craniofacial region. Plast Reconstr Surg 65:553-560

57. Bostrom R, Mikos A (eds) 1997 Tissue engineering of bone. Birkhauser, Boston, pp 215-234

58. Mofid MM, Manson PN, Robertson BC, Tufaro AP, Elias JJ, Vander Kolk CA 2001 Craniofacial distraction osteogenesis: a review of 3278 cases. Plast Reconstr Surg 108:1103-1114; discussion 1115-1107

59. Zuk PA, Zhu M, Mizuno H, Huang J, Futrell JW, Katz AJ, Benhaim P, Lorenz HP Hedrick MH 2001 Multilineage cells from human adipose tissue: implications for cell-based therapies. Tissue Eng 7:211-228

60. Cowan CM, Shi YY, Aalami OO, Chou YF, Mari C, Thomas R, Quarto N, Contag $\mathrm{CH}, \mathrm{Wu} \mathrm{B}$, Longaker MT 2004 Adipose-derived adult stromal cells heal critical-size mouse calvarial defects. Nat Biotechnol 22:560-567

61. Yoon E, Dhar S, Chun DE, Gharibjanian NA, Evans GR 2007 In vivo osteogenic potential of human adipose-derived stem cells/poly lactide-co-glycolic acid constructs for bone regeneration in a rat critical-sized calvarial defect model. Tissue Eng 13:619-627 